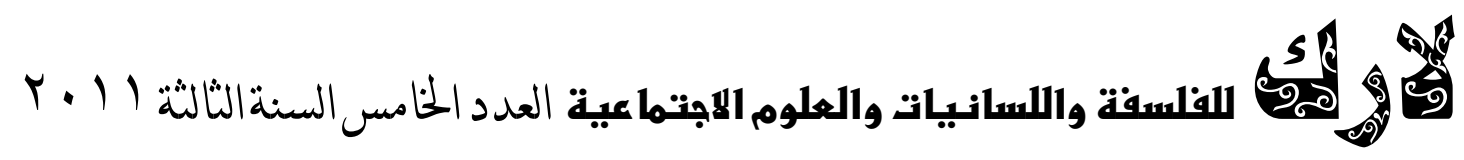

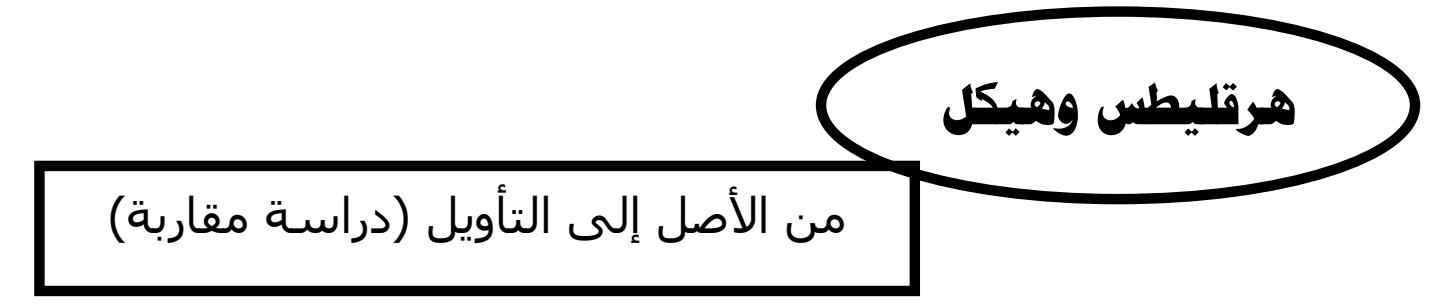

أ. م. د. حامد حمزة حمد

كلية الآداب - جامعة وا1ط

مقدمهة:

الفكر الإنساني بكل جوانبه، كل واحد لا يتجزأ، ولا يمكن أن تكون حلقاته غير مرتبطة ببعضها عبرة مسيرة التاريخ التي توجب تطوره من الماضي إلى الحاضر،إلى حد لا يمكن الاحتكام فيه إلى أصل المذاهب الحديثة إلا بالعودة إلى الأصول التي سبقتها، وفي هذا فائدتين

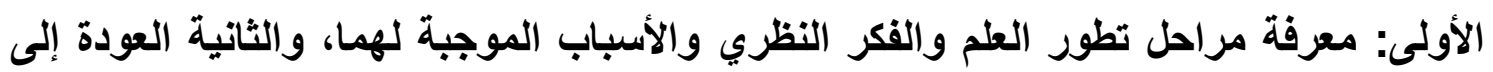
الأصول الأولى لولادة الأفكار ومقاريتها مع حاضرها لمعرفة مدرى مدى تطابقها مع بعضها. والقلسفة

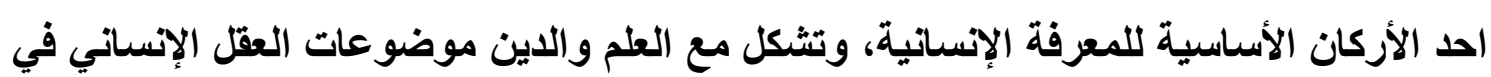

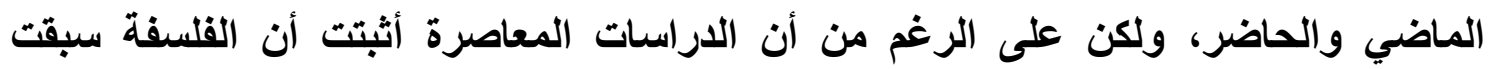
اليونان، ألا أن مفهوم القلسفة لفظة استحدثت مع اليونان في القرن السادس قبل الميلاد، ومعهم تطورت بفروعها ومباحثها وبلغت أوجها مع أفلاطون وأرسطو في القرنين الثالث والرابع قبل الميلاد.

كانت القلسفة اليونانية موضوع اهتمام الباحثين والدارسين على مر العصور، حتى بعد أن أغلقت المدارس القلسفية اليونانية في العصر الروماني، بحجة أنها تدرس الأفكار الوثنية

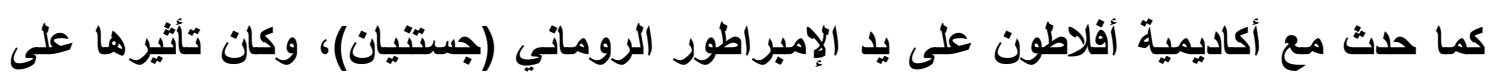

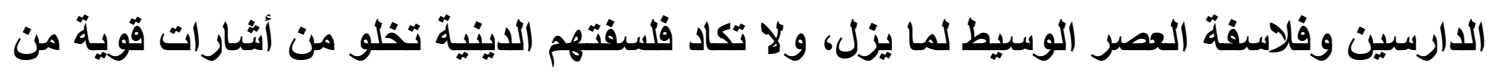
القلسفة اليوناتية، سواء كان ذلك في الجاتب الأخلاقي أو القلسفي. وكان هناك رابطا مهما بين

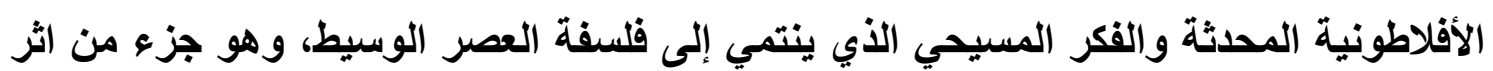
القلسفة اليوناتية عليه، كما أطلق على القديس أوغسطين لقب (أفلاطون المسيحي)('). وفي العصر الحديث اخذ الاهتمام بالفكر اليوناني حيزا كبيرا من فكر الباحثين والفلاسفة، وترجمة الكثير من كتب الفلاسفة اليونان ومؤرخو الفكر اليوناني حتى أغتت الفكر الحديث وألقت بضلال أفكار ها على تصورات فلاسفته وهيمنت على عقولثه. 


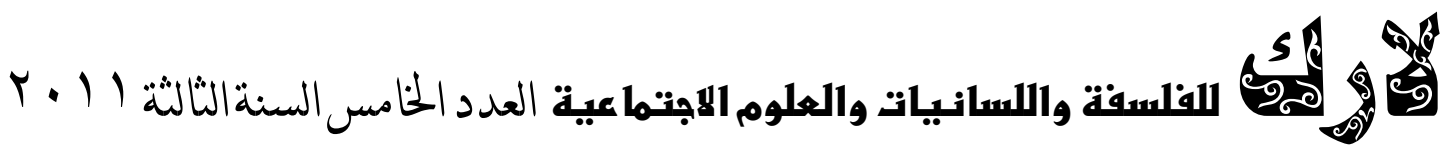

لقد أثبتت الدراسات الحديثة أن التاريخ يتطور عبر مراحل وحلقات يرتبط بعضها ببعض،

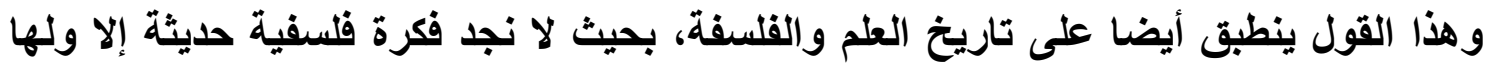
جذورها في الفكر القديم، بعد أن خضعت لسلسة التطور التاريخي . أن أهم نقطة في تشابهه عصر التهضة والحديث مع العصر اليوناني القديم، هو أن الدافع

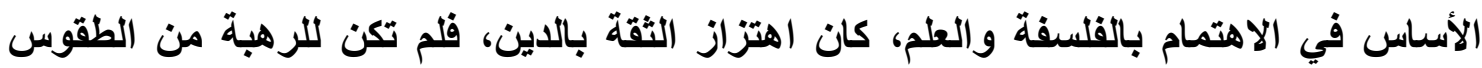
الاينية والمعابد في أيونيا في القرن السادس قبل الميلاد أدنى تأثير على طبقة المثقفين على اقل تقدير، بعد أن افقدها هوميروس إنساتيتها وقدسيتها حينما وصفها بأوصاف مشينة في أشعاره الملحمية التي حطت من أهميتها في نظر الناس، وهكذا كان حال الدياتة في عصر النهضة التي اهتزت الثقة بها بعد أن أفرغتها الكنيسة من محتواها الديني وسيستها، وكان ذلك سببا ملحا في وهي التوجه نحو العلم والقلسفة.

أن نظرة فاحصة لمسار الفكر القلسفي الحديث والمعاصر، يمكن الاستثتاج منها، أن معظم

الأفكار القلسفية التي ظهرت في هاتين العصرين لا تخلو من اثر للفكر اليوناني القديم، وان

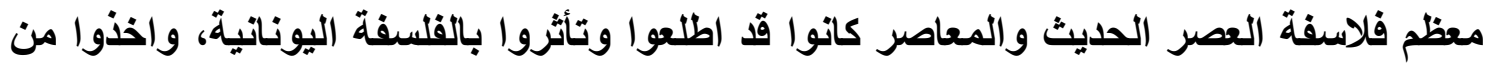
أفكارها في بناء مذاهبهم في القلسفة، مثل فرانسس بيكون وامانوئيل كاتت وهيكل ونيتشه

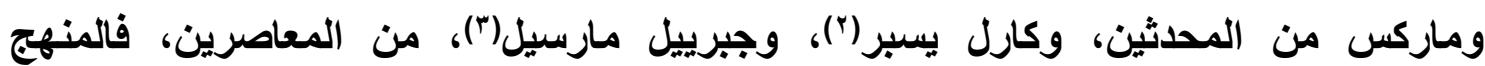
الاستقرائي عند بيكون قام على أساس المنهج الأرسطي، فضلا عن أن بيكون احتفظ من أرسطو بمصطلح الصورة التي كاتت احد أركان فلسفة الأخير في الوجود(؛)، كما تميزت القلسفة الانكليزية(متمثلة بجامعتي كمبردج وأكسفورد)، منذ العصر الوسيط، بالنزعة الروحية الأية الأفلاطونية للأولى والأرسطية للثانية، في حين قامت فلسفة هيكل على فكرة الصراع والجدل التي قال بها هرقليطس، في حين يرى بعض مؤرخوا القلسفة أن جذور القلسفة الوجودية يعود

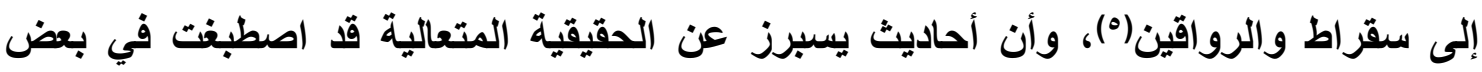
الأحيان بصبغة أفلاطونية محدثة(؟)، وكان السبب في ذلك إلمامه بالتراث الفلسفي الهائل الأي خلفه سقراط وأفلاطون وأرسطو والرواقين وغيرهم من فلاسفة العصر اليوناني القديم، أما مارسيل فقد اثر على تسمية فلسفته بالسقراطية الجديدة، وأطلق علية اسم سقراط الجديد، لأنه أراد للقلسفة أن تكون فلسفة واقعية، كما هي عند سقراط، وفضلا عن ذلك فان نظرة مارسيل إلى الوجود تثبه إلى حد كبير رأي بارمنيدس، فقد رأى الأول أن الهدف من القلسفة هو أدراك الوجود من حيث هو موجود (الوجود العام)(V)، وهو ما قصده بارمنياس في قصياتته في

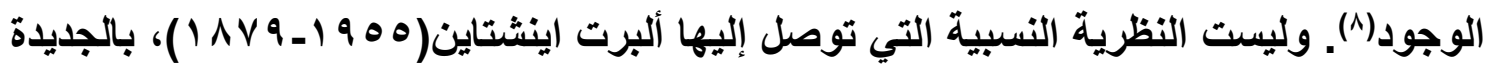
على الفكر الإنساني، فالسفسطائيون أقاموا أرائهم في القلسفة والأخلاق على قاعدة نسبية تعد الإنسان مقياس كل شيء، والشكاك في القرن الرابع قبل الميلاد، شكوا بكل روافد المعرفة 


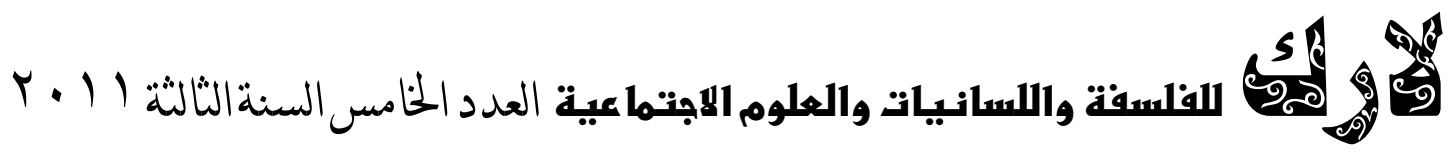

الإنساتية، وتوصلوا إلى عدم قدة الحواس والعقل على الوصول إلى المعرفة بطبيعة الأشياء، واخذوا بمبدأ التوقف عن الإقرار بأي شيء وتعليق الحكم.

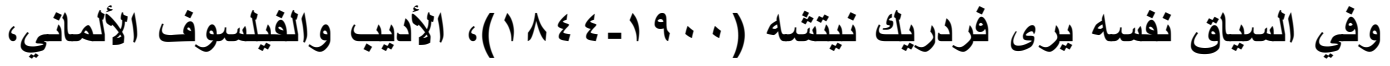

الأي كان يشبهه هرقليطس، فقد كان أبوه قسيسا، وجده هو الأخر كان قسيسا، وفي شبابه أراد أن يكون قسيسا، لكنه خرج عن الدين والأخلاق بمنتهى الثدة، وصار عالما من أعلام الفكر(9)، يرى أن علينا التميز بين البداية والأصل، لأنه ليس ممكنا الحديث عن الأصل، لان كل أصل

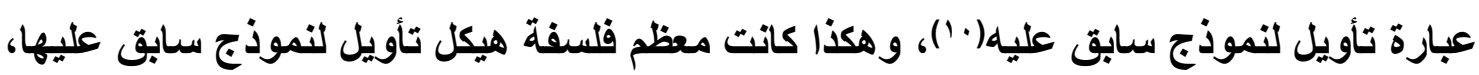
وهي أراء هرقاليطس في القلسفة.

وفي بحثنا المتواضع هذا نود أن نبين اثر فلسفة هرقليطس على فكر هيكل وإنتاجه الفسلفي من خلال مقاربة الأفكار الأساسية عند الاثنين، وبيان اسبقية هرقليطس في ذلك من خلال استخدام المنهج التاريخي المقارن، واعتماد النصوص الأصلية عند الاثنين لتفادي الوقوع هلئ في الزلل.

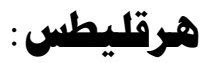

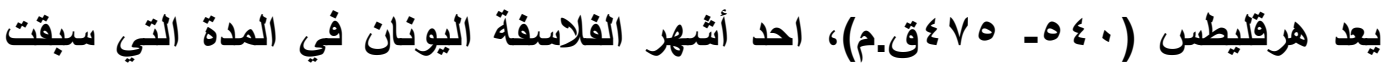
سقراط، وينظر إليه دائما بوصفه مدرسة فلسفية مستقلة، وفي اغلب الأحيان يصنف ضمن فلاسفة الطبيعة بسب إرجاعه مبدأ الوجود إلى عنصر طبيعي مادي هو(النار). ينحدر أصله من عائلة ارستقراطية اشتهرت بالكهانة، وحينما توفي والده تنازل عن منصب الكاهن لأخيه الأصغر، بسبب نظرته الساخرة للاين ومحاولته التخلص من قيوده وعلائق المجتمع، الأي كان يرى أن جل أهله لا يعرفون كيف يسمعون ولا كيف يتكلمون. لقد كان ذا طبيعة متعالية يحتقز العامة ومعتقداتهم ويباعد بينه وبينهم، يشبهم بالكلاب تارة،

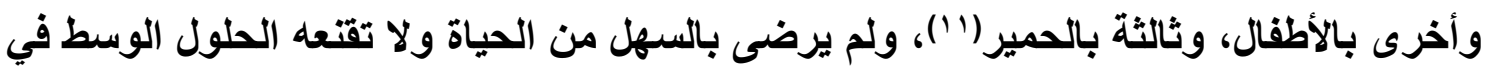
المسائل القلسفية أو الاجتماعية، لذلك كان يزدري العلم الجزئي والمشتخلين فيه أمثال هوميروس وهزيود وفيثاغورس، ويرى(انه لا يثقف العقل)، بل كان يتجه في تفكيره وفلسفته إلى أصعب الأمور وأكثرها تعقيدا وغموضا، لألك لقب(بالفيلسوف الغامض). لقد اعتمد في أسلوبه الرمزية والتثبيه واستعمال العبارات المبهمة بطريقة نثرية، ويعد دون أدنى شك والكويل مؤسس الجدل في القلسفة، وقد سبق سقراط في أشارته إلى أن العلم الوحيد الجدير بالاهتمام

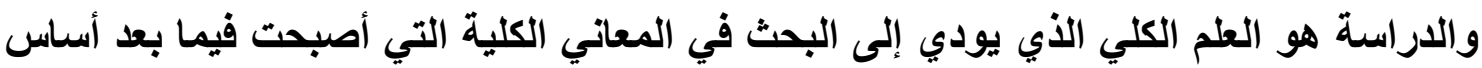

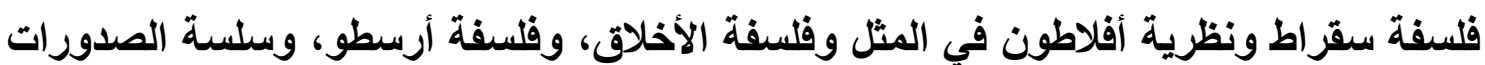

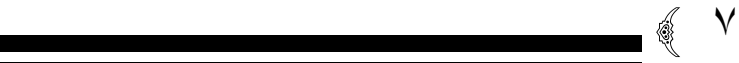




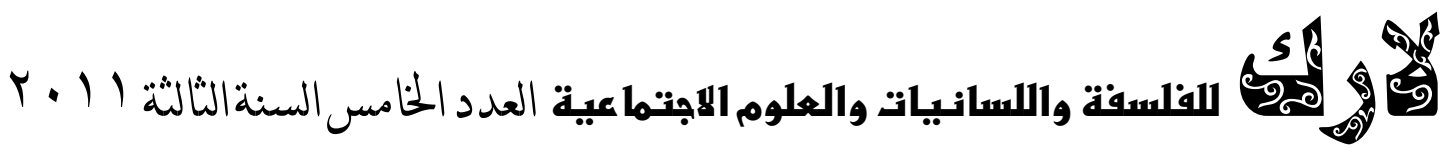

في الوجود عند أفلوطين، وصراع المتناقضات عنده سر إدامة الكون والحياة ، وسنفصل القول في ذلك لاحقا.

أن البحث في فلسفة هرقليطس ليس بالجديد، فقد تباينت أراء الباحثين في العصر القديم والحديث حول فلسفته عامة وأسلوبه الغامض خاصة، وكان أشهر منتقديه معاصره (بارمنيدس

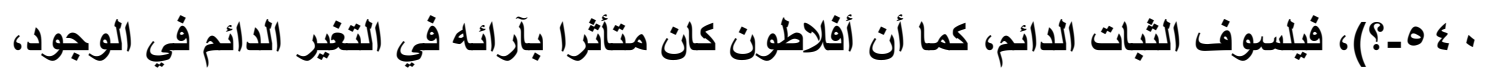
وكان ذلك السبب الأساس الأي دفعه للبحث عن عالم الثبات الدائم خارج الوجود الحسي

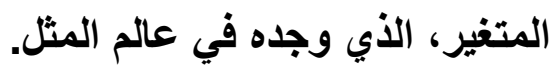

لقد استطاع هرقليطس أن يثري بفكره الأصيل والجريء مسار الفكر القلسفي، ويوجهه نحو المتغير والمتحرك والمتجدد والمتعدد، الأي هو مبدأ الوجود المادي (النار الأزلية)، والتناقض والصراع الدائم (الأي هو سر إدامة الوجود)، الذي يخضع برمته للمبدأ الميتافيزيقي الأي يمثل الحقيقة الوحيدة الثابتة في الوجود (اللوغوس أو القانون).

أن هذه الأفكار الأصيلة التي تجعل من التناقض(الجدل)، أساس الصراع في الوجود، تشيد

بثخصيته القلسفية الفذة، التي جعلت منه فيلسوفا من الطراز الأول، مما كان مدعاة للإثادة به هنه من قبل الكثير من الفلاسفة والباحثين قديما وحديثا، فقد قال فيه ديوجين اللايرسي قديما: (كان هرقليطس رجلا سامي المشاعر، متكبرا، متعجرفا، أكثر من أي إنسان أخر وكان منذ حداثته

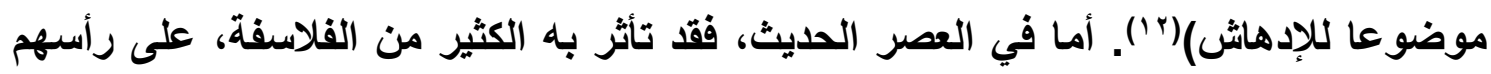
هيكل، موضوع بحثنا، حيث قال فيه:(انه لأمر عظيم الأهمية أن يكون هرقليطس أدرك أن هونيز الوجود واللا وجود هما مجرد تجريدات لا حقيقة لها ،وان الحقيقة الأولى هي الصيرورة فقط)(rّ). وكان فردريك نيتشه من المعجبين به أيضا، فقد وصفه قائلا: (أن من رأى مذهبه في القانون داخل الصيرورة، وفي اللعب داخل الضرورة، يجب أن يبقى من الآن فصاعدا حاضرا في من في الذهن إلى الأبد، انه هو الأي رفع الستار عن هذا المشهر المهيب)(؛؛)، في حين عده كل من الن

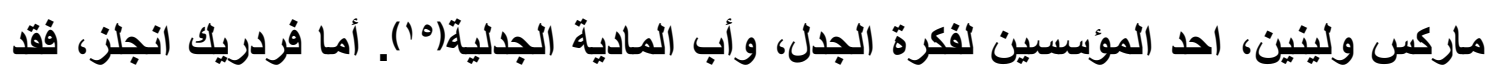
وصف منهجه بالصحيح في الجوهر، إذ يقول فيه: (أن تلك الطريقة البدائية الساذجة، أنما الصحيحة في الجوهر، في النظر إلى العالم، هي طريقة الفلاسفة اليونان في العصور القديمة،

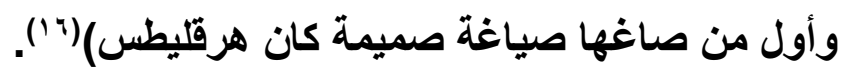




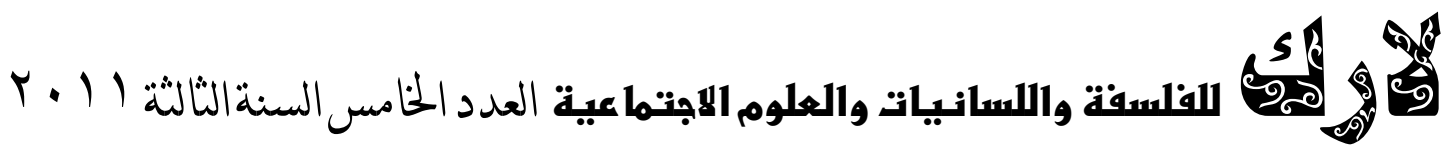

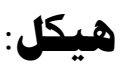

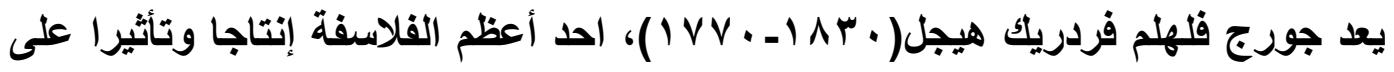
مسار الفكر القلسفي من بعده، وتثكل فلسفته المثالية ونقدها، جزاء مهما من تاريخ القلسفة

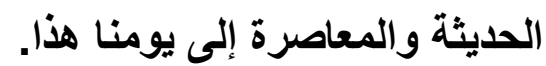

لقد بلغت مؤلفاته حوالي ثلاثون مجلدا، أربعة منها تم نشرها في حياته، وهي: (علم

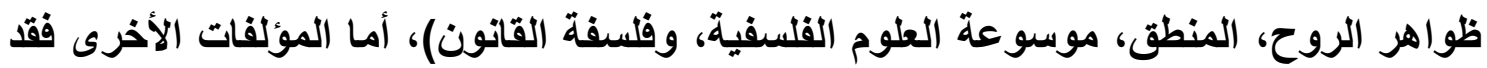
نشرت بعد وفاته وترجمت إلى اللغة الانكليزية وهي: (محاضرات في فلسفة التاريخ، وفلسفة

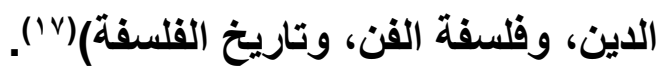

تميز هيكل بأسلوب لامعا، بليغا، زاخرا بالصور، ونقده للكنيستين الكاثوليكية والبروتستانتية على السواء، بل وحتى السيد المسيح، نقا لاذئعا في اغلب الأحيان، فقد كان يعارض كل عقيدة متحجرة أو نزعة إلى السلطة، لقد كان يعتقد أن المسيحية كدين تثنافى مع العقل والكرامة الإنسانية، وكان يبحث عن أمكان قيام دين معقول تمام المعقولية، من شانه أن

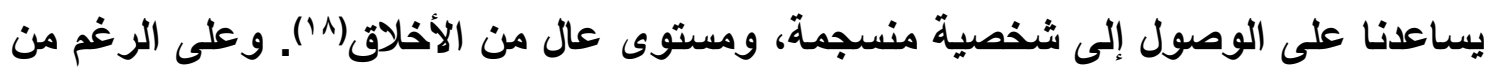

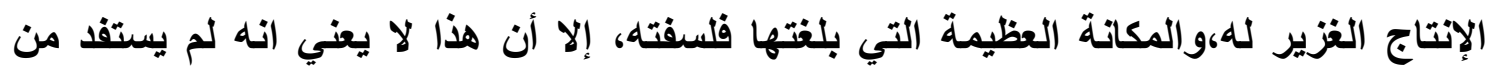
المذاهب السابقة عليه، خاصة القلسفة اليونانية القديمة.

مثل هيكل الاتجاه المثالي في القلسفة الحديثة، وكان أفلاطون مؤسس هذا الاتجاه قد جمع في شخصه كل مزايا العقل اليوناني، فأوصلها إلى أقوى وأبهى مظاهرها، وتميز بالجراءة والاستدلال والحدس والملاحظة، فضلا عن العاطفة والفن والرياضة، واستوعب جميع النزعات

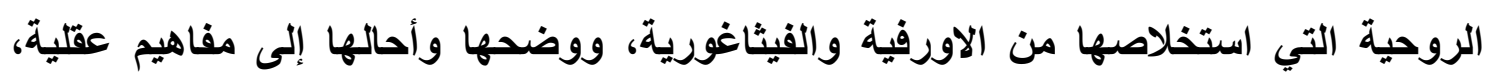

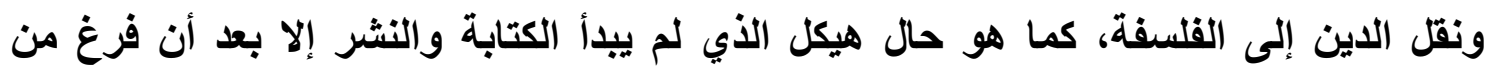
تكوين مذهبه بجميع تفاصيله، مستخدما في ذلك ثقافة واسعة ودقيقة في القلسفة والعلوم

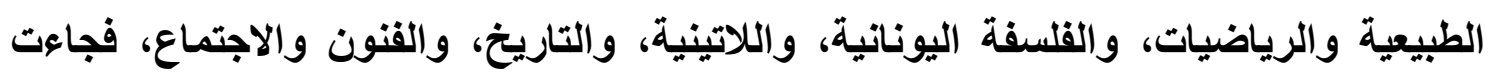

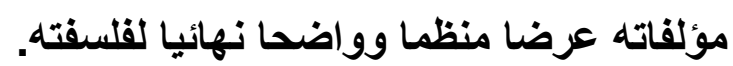

وفق أفلاطون ونسق بين المذاهب المختلفة، وعد كل واحدة منها حقيقة جزئية، وان

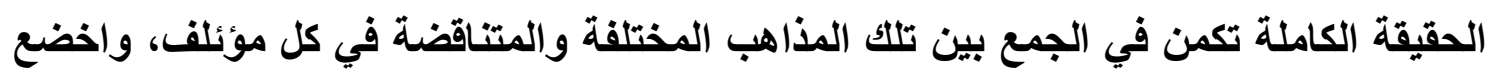
المحسوس للمعقول والحادث للضروري، وكان اثر فلسفة هرقليطس في صراع الأضداد الأي يولا الحياة،احد العوامل الرئيسة المؤثرة فيه،وهكذا فعل هيكل في العصر الحديث،متأثرا بآراء 


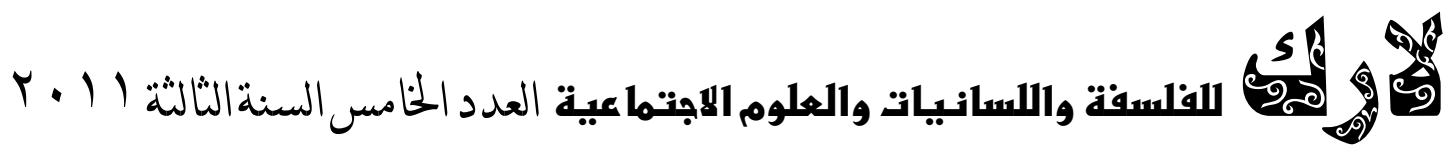

هرقليطس في الوجود، ومنهج أفلاطون في التوفيق بين المذاهب،وفلسفته المثالية، وطريقة أرسطو في كتابة ونقد الاساتير.

ومن الجدير بالملاحظة أن فلسفة هيكل لم تسلم من النقد حتى في حياته، فقد تعرضت للتقد الثديد من قبل أصدقاءه وتلامذته، وهو مازال على قيد الحياة، واستمرث مدة طويلة بعد وفاته، وكان أول منتقديه زميله (هولزمان)، فقد كان كتابه الذي عنوانه حول النظرية الهيظلية أو المعرفة المطلقة ووحدة الوجود الحديثة، نقد موجها ضد فلسفة هيكل، ثم كتاب (شوبارت)،

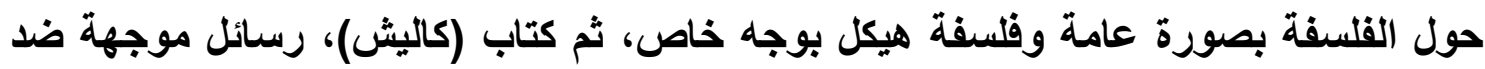
موسوعة هيكل للعلوم القلسفية، ولكن اخطر الهجمات على فلسفة هيكل كاتت من قبل هون

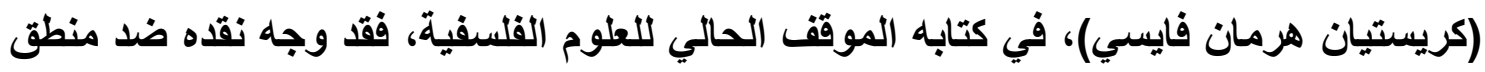
هيكل، وكاتت حجته أن هيكل لم ياخل الزمان والمكان ضمن مقولات المنطق، وان مزاعم منطق هيكل مبالغ بها، وفي كتابه(مذهب في علم الجمال)، رأى هايسي أن هيكل انتهى إلى الوقوع في الشمولية المنطقية، في نظريته عن الروح المطلق، حيث يضع العلم، أي الفلسفة فوق الفن مان والدين، بدلا من أن ينتهي مذهبه بالدين، كما انه احل الفكرة المطلقة محل الله، وبذلك وقع في الته وحدة وجود منطقية شاملة، حيث يرى هايسي أن على هيكل أن يعترف بالحرية التي تتجاوز ما مانس

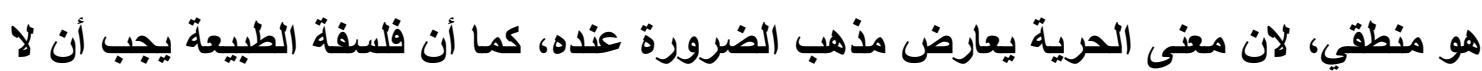
تكون بناء منطقيا، بل أن تتحول إلى تجربة فلسفية. لقد عد هايسي فلسفة هيكل مجموعة متسقة من الأخطاء، وان مذهبه، هو مذهب في وحدة الوجود أو الإلوهية الشاملة، على الرغم

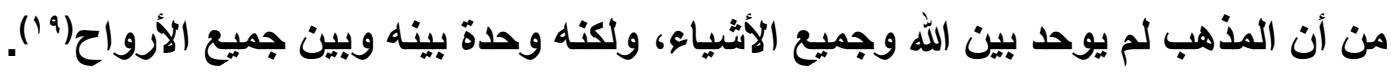

هقاربات:

اللوجمود:

يرى هيكل أن المطلق هو الوجود الواقعي بما فيه من روح لأمتناه، وعقل كلي، أو مبدأ خالق منظم، وان الطبيعة والفكر مظهران من مظاهره، يظهر الفكر في وقت ما من تطور الطبيعة، لأنهما وجهان له متوازيان، ولأجل فهم الوجود في مبدأه وتسلسل مظاهره يجب أتباع

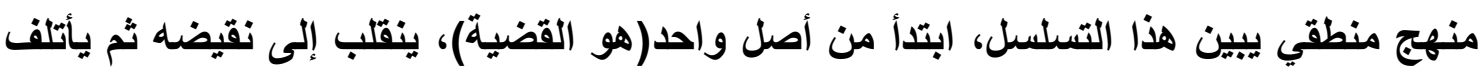
مع هذا النقيض(r). أما الموجود حقا عند هيكل فهو المركب من نقيضين، الوجود واللا وجود(الموجود الذي لا يوجد على التمام)، وهذه هي الصيرورة، فهي عنده صميم الوجود وسر التطور، والصيرورة هي وجود لا وجود (ما سيصار أليه)، وهي ليست اجتماع الأضداد أو

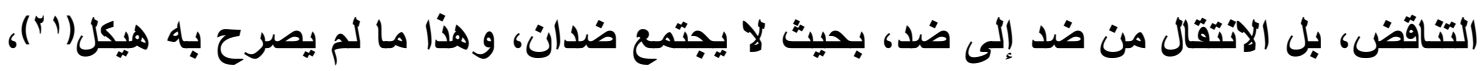




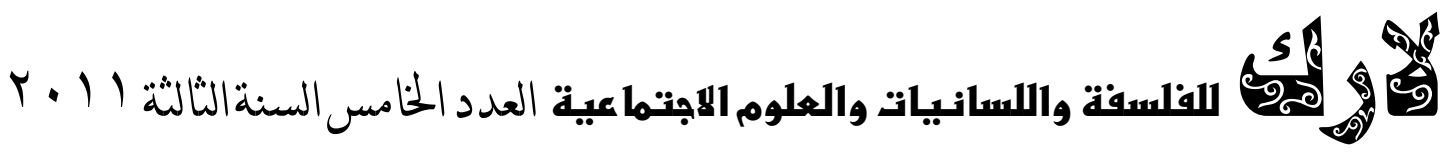

وهو أصل قول هرقليطس بالوجود المتحرك المتبدل على الدوام، وبناء على ذاللك يعد الموجود صائرا وناميا، والتناقض ماهية تتجلى في متناقضات العقل، لان التناقض عند هيكل مبأ أول في العقل والوجود، وما ذاك إلا لأنه ظن أن الوجود أطلاقا، هو الوجود المحسوس الصائر

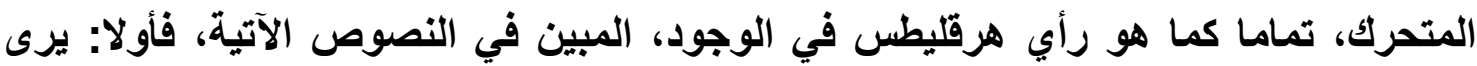
هرقّيطس أن الوجود مركب من نقيضين:(الزوجان كل ولا كل، يرسمان معا وإحداهما تحت هري الأخر، مؤتلفان ومتنافران، الواحد يتألف من جميع الأثياء، وتخرج جميع الأثياء من من هن الواحد)(rr)، وهذا يعني أن كل كائن وليا الصراع بين قوتين متناقضتين، مؤتلفتين (الوجود واللا وجود)، لا تهآن برهة حتى تعودان إلى التنافر والتنازع، وتتنازعان حتى تعودان إلى الائتلاف والانسجام، هذا الصراع يحوي جميع الأشياء،وجميعها تخرج منه، فالوجود أذن تنازع وصراع بين الأضداد، والصراع قاعدة في الوجود تخضع لها جميع الموجودات، وحتمية

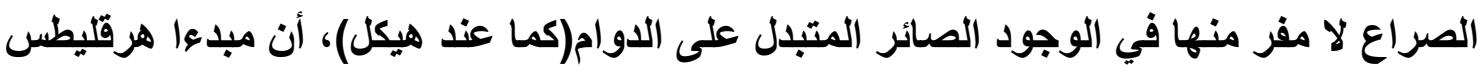
قائم في الصيرورة والتغير(الموجود وحده)، وما الوجود الثابت إلا وهم،فكل ما يوجد في عالمنا هو في حالة تغير دائم ويتحول إلى أشكال جديدة من الوجود،فلاشيء يبقى ويثبت ويظل كما هو، يقول هرقليطس: (يجب على الإنسان أن يعرف أن الحرب عامة والشريعة هي النزاع وكل شيء

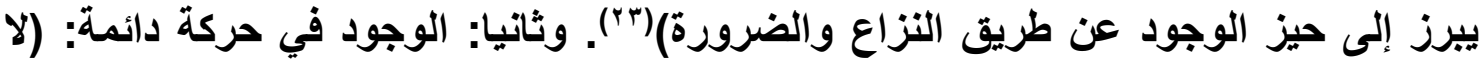
يمكنك أن تثزل مرتين إلى التهر نفسه، لان مياه جديدة تغمرك باستمرار، وهي تتجمع

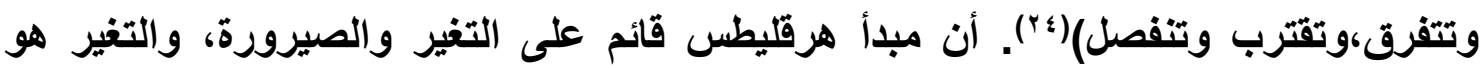
الموجود وحده، وما الوجود الثابت إلا وهم، فكل ما يوجد في عالمنا هو في حالت تغير دائم ويتحول إلى أشكال جديدة من الوجود، فلاشيء يبقى ويثبت ويظل على حاله ولو للحظة واحدة،

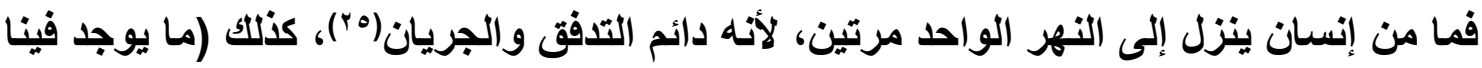
شيء واحد: حياة وموت، يقظة ونوم، صغر وكبر، فالأولى من الأضداد تتحول وتصبح الأخيرة،

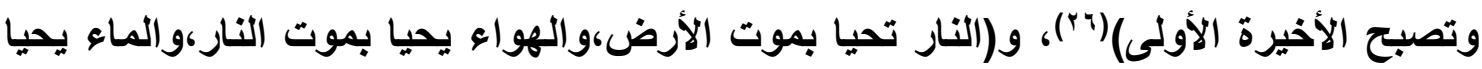
بموت الهواء،والأرض تحيا بموث الماء)(rV)، (وتصبح الأرض بحرا طبقا لتفس القانون الأبي تحولت إليه الأرض من قبل)(^^)، (تتجدد الشمس كل يوم،وهي علة تغير الفصول التي تتتج كل

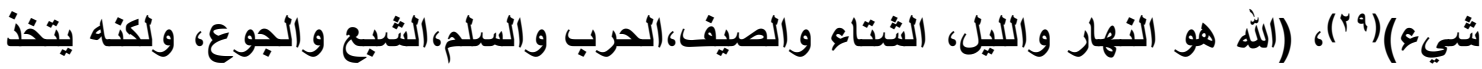

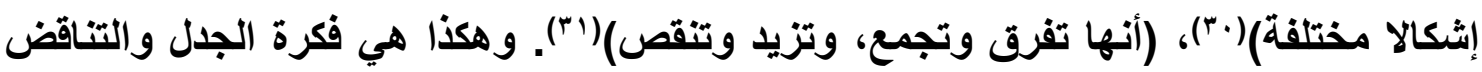
والصيرورة، وهي سر إدامة الحياة عند الاثنين.

أما من ناحية علاقة الفكر بالوجود عند هيكل واثر هرقليطس عليه فيرى الأول، أن الفكر

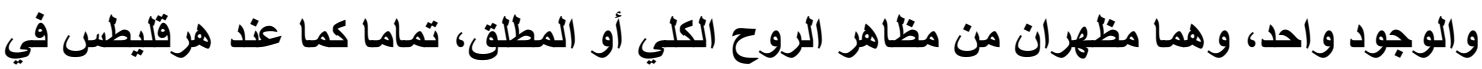

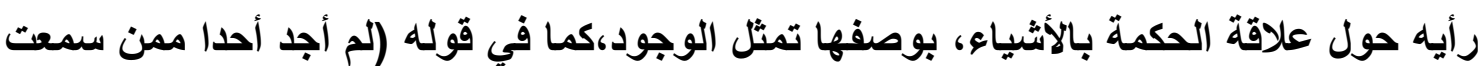




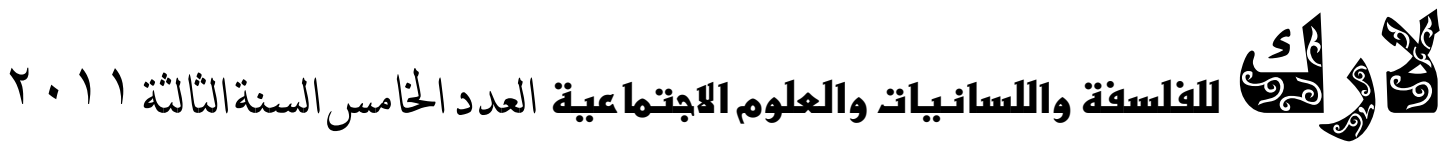

مقالاتهم يذهب إلى أن الحكمة منفصلة عن جميع الأثياء)('آأ)، وهو يقصد بالحكمة، المعرفة، وجميع الأثياء، الوجود،في حين أن الحكمة عنده شيء واحد هي معرفة ما به تتحرك جميع

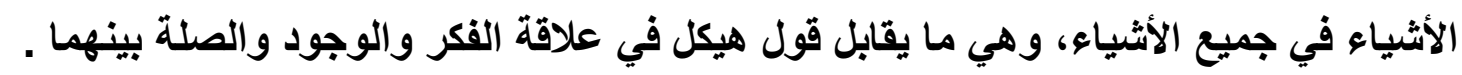

\section{القانون والمتتمع:}

أن العصر الأي عاث فيه هرقليطس وما ساده من حروب بين دويلات المدن اليونانية

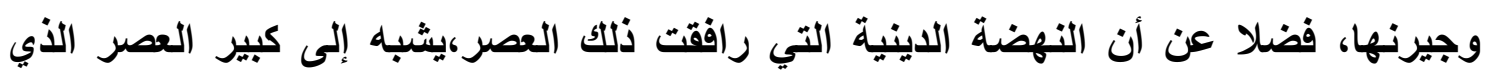
عاش فيه هيكل، فألمانيا في عصر النهضة كانت عبارة عن حشد من الدويلات الصغيرة، وكان الموقف السياسي فيها عبارة عن فوضى سياسية وقاتونية. وهكا ظروف تمتاز بظهور الشخصيات الفردية البارزة، ومن شان الفردية العزلة، وهكذا كاتت الحال مع هرقليطس وهيكل، وهيك، وهيك.

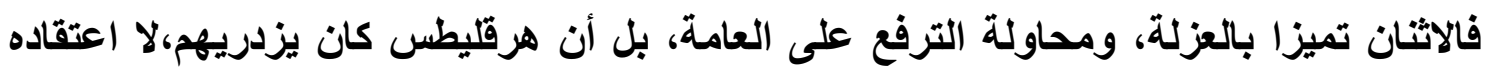

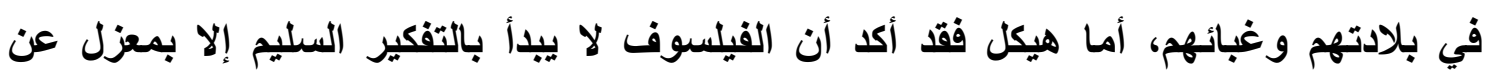
العامة، وقد جسد ذلك في قوله الثهير (أن بومة منيرفا لا تبدأ الطيران إلا بعد أن يرخي الليل

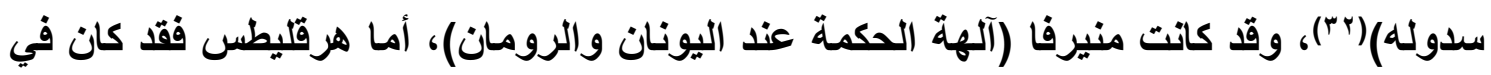
معظم أقواله يحاول إيقاظ أذهان العامة للبحث عن الحقائق التي تحب أن تختفي، وان لا يتركوا ذلك لأنهم سوف يقتعون بالمظاهر الكاذبة،لان (الطبيعة تحب أن تختفي)(rّم)، كما يذكر أن (الناس يعجزون عن فهم الكلمة لوغوس (القانون)،الأزلية عند سماعها وكأنهم يسمعونها لأول مرة، وان الأشياء تسير مطابقة لهذه الكلمة، إلا أن الناس يبدون كأنهم لا تجربة لهم بالأشياء

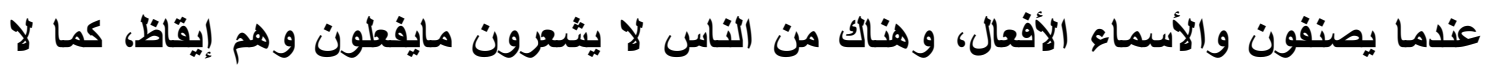
يشعرون ما يفعلون وهم نيام)(๕ّ). كما أن قصور فهم الناس لمظاهر الحياة جعلهم حسب رأيه، لا يفهمون الأمور التي تقع عيونهم عليها، إذ يقول (لا يفهم كثير من الناس هذه الأمور التي تقع عيونهم عليها، ولا يلحظونها حين يعلمونها، ولو أنهم يظنون غير ذلتك)(ror). لقد عد هيكل القلسفة فكر ثاني، أو فكر لاحق، وهناك فكر أول ينشا في حياة الناس اليومية في شتى المجالات، ثم تأتي القلسفة لتجعل من هذا الفكر موضوعا للاراسة، ودور القلسفة هنا توجيه نظم الفكر الأول (الحياة اليومية للناس)، وترتيبها بالشكل الأي يجعلها تثطابق مع الكلي أو القانون العام الأي تمثله التصورات الكلية التي هي موضوعات القلسفة الرئيسية النابعة من العقل الأي يمثل الكلي، ولان الناس عاجزين عن ذلك، فان تلك المهمة تقع فئه على عاتق القلسفة. وهذا ما يطابق أفكار هرقليطس في القاتون العام أو اللوغوس. 


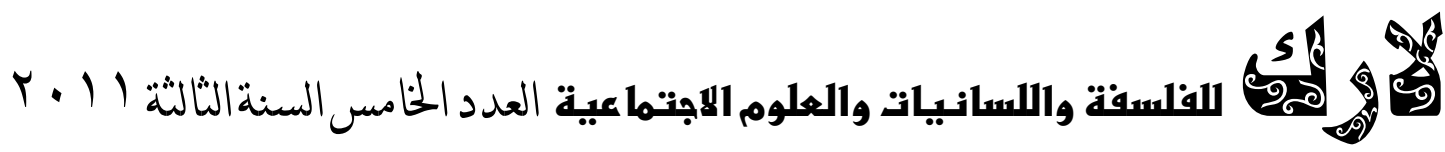

ومن الجدير بالملاحظة ان الاثنين لم يبتعدا عن الواقع في معالجتهما للإلسفة والقانون، بل أن الواقع هو مجال البحث القلسفي والأخلاقي والسياسي في محاولتهما وضع نسث من النظم الكلية في تنظيم الحياة الاجتماعية، وما فيها من تنظيمات سياسية وقوانين. لقد انتقد هيكل المجتمع المدني الأي عاش فيه،وكان في رأيه مجتمعا مفككا،والسبب في ذللك لأنه خرج (أي المجتمع)، من أسرة مفككة يكون الفرد فيها عبارة عن جزئية في خلية اجتماعية صغيرة تكون هي غايته وهدفه، وهي غاية كلية،ولكن تفكك الأسرة جعل كل واحد من أعضائها عبارة عن غاية في ذاته، لطالما يحول أن يتعامل مع الآخرين على أنهم وسائل

لتحقيق غاياته الجزئية الخاصة(باتهان.

\section{البدل والصراع :}

أن مبدأ هرقليطس في الوجود قائم على الصراع والجدل، وان كل شيء هو وليد الصراع بين قوتين متناقضتين، لا تهأن ولو للحظة واحدة، ثم تعودان إلى التتافر والصراع، ولا تتنازعان حتى تعودان إلى الانسجام والائتلاف، فالوجود عنده تنازع وصراع بين الأضداد، والسبب الذي قاد هرقليطس إلى افتراض الصراع هو ما رآه في المبدأ الأول الذي افترضه كأصل للوجود وهي( النار)، فان من صفاتها سرعة الحركة والتحول وعدم الثبات على حالة واحدة في اللحظة الواحدة، بل هي في تبدل باستمرار، وهكذا حالة الوجود، فهو قائم على التغير والصيرورة، وما حالة الثبات الأي نراها إلا وهم، فكل شيء يتبدل ويتغير باستمرار، ويقول في ني

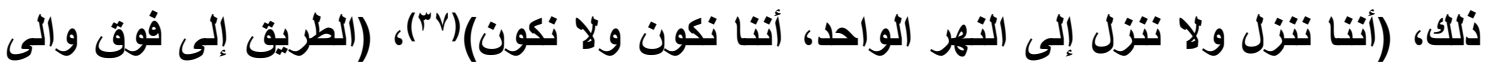

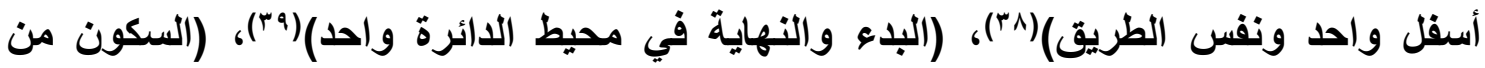
(التغير)(· ( ).

أن حقيقة المذهب الهرقليطي التي تقر بالتغير المستمر في الوجود، تعد مبدأ أساسيا من المبادئ التي قامت عليها المذاهب القلسفية الحديثة منها والمعاصرة، وأهمها مذهب هيكل الذي لئي يعد الجدل والصراع من دعائم الوجود الأساسية، وان كل مقوله من مقولات الوجود تحتوي على ضدها، من خلال المبدأ العام لمنهجه المتمثل بالمثلث الهيكلي (الوجود، العدم، الصيرورة)، فالوجود هو الجنس، والصيرورة هي لون خاص من ألوان الوجود وهي وجود يتضمن في داخله سلبه أو ما يسمى بالكلا وجود، ومن جمع فكرة الوجود واللا وجود تظهر لنا فكرة الصيرورة، أما العدم فهي حالة الفصل بين الوجود والتلا وجود(1؛). وهكا فان كل مقولة من تثلك المقولات الثلاثة يعد طرف أساسيا من أطراف الصراع في فلسفة هيكل بشكل عام، ونظرته إلى الوجود بشكل خاص، حيث أن المقولة الأولى تمثل الإيجاب 


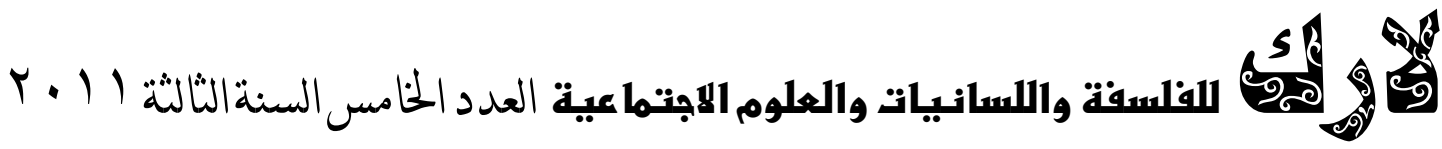

أو الإثبات، وتضع نفسها كفرض ايجابي مثل الوجود موجود، في حين تكون المقولة الثانية

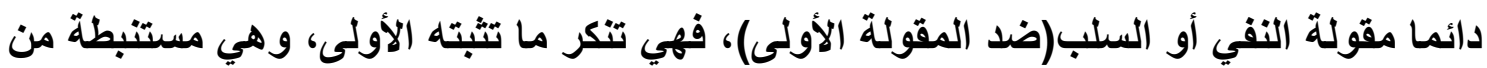
المقولة الأولى، وهذا يعني عنده أن المقولة الأولى تتضمن الثانية، وان الأخيرة خرجت منها، الثانها

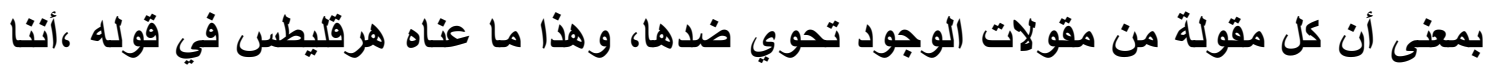
ننزل ولا ننزل إلى النهر الواحد، أو نكون ولا نكون، والطريق واحدة إلى أعلى وأسفل... الخ.

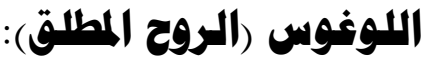

يقول هرقليطس في باية كتابه (في الكل)، من الحكمة أن لا تصغوا أليًَ، وان تقولوا أن الن النيا

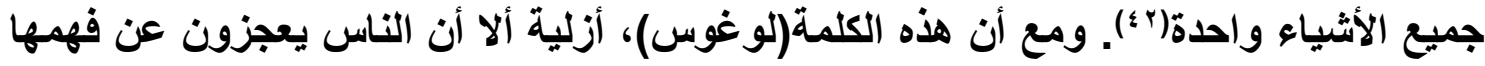

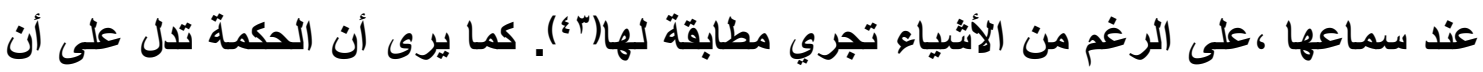

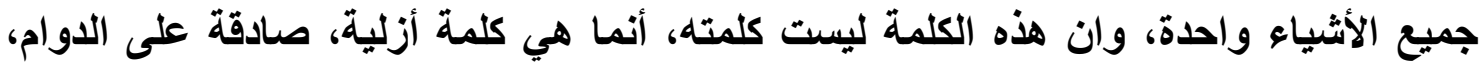
وهي الحق، وهي مطلب جميع الحكماء في جميع الأزمان، وهي التي أثشار أليها هيكل في التياء

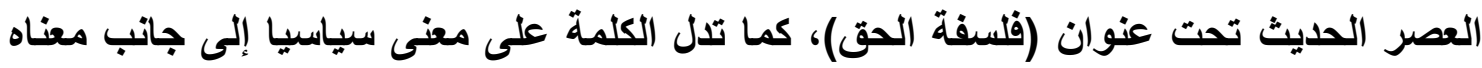
الديني والاجتماعي والأخلاقي، ويتضح ذلك من عبارات هرقليطس المختلفة التي يؤكد فيها

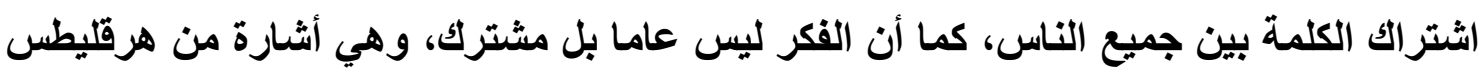

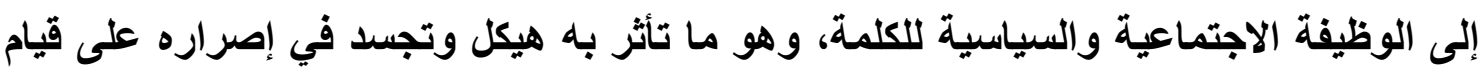

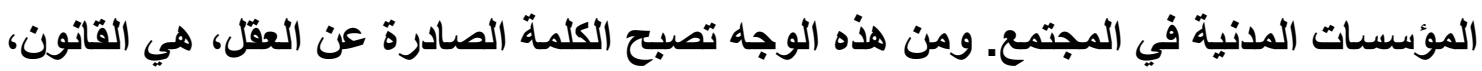

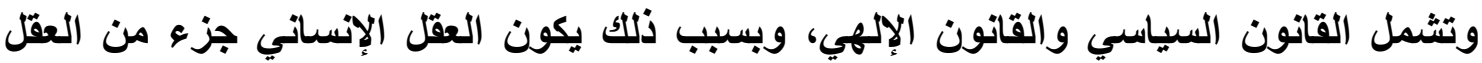

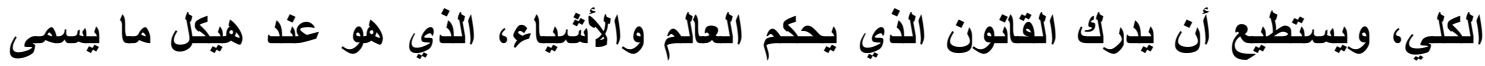

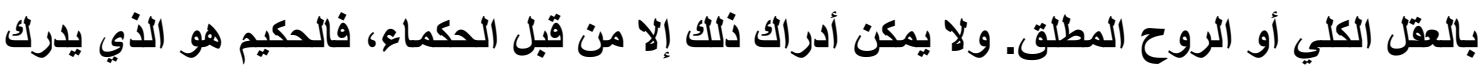

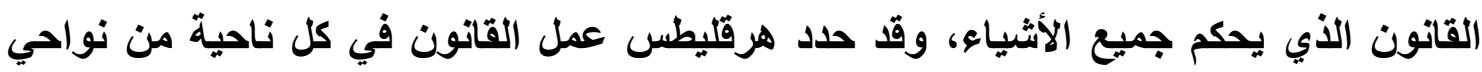

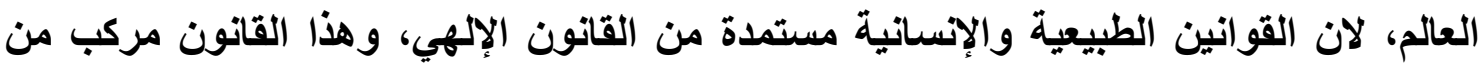

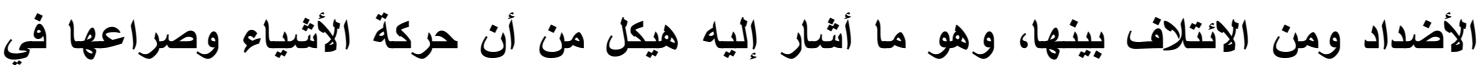

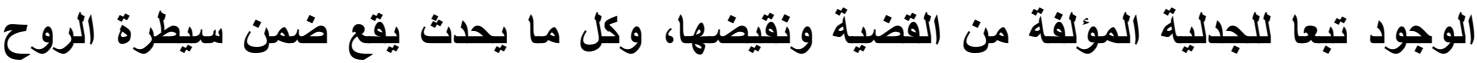

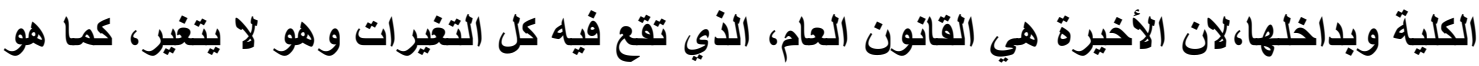
اللوغوس عند هرقليطس، الذي يسيطر على كل شيء في الوجود وهو ثابت لا يتغير، وهو

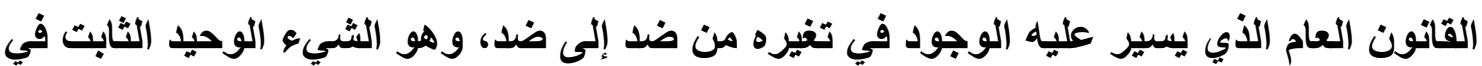
هذا الوجود الدائم السيلان( ؛ ؛). أما هيكل فينظر إلى الوجود على انه الفكرة الأكثر تجريدا والأكبر كلية، ولذلك فهي الأكثر

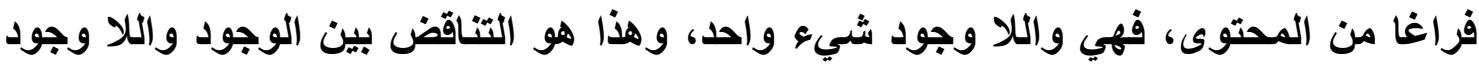




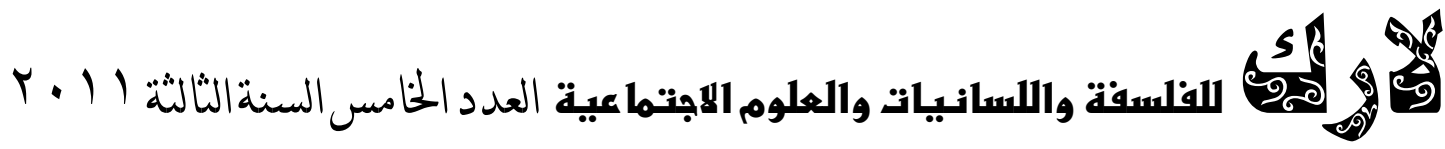

والصيرورة أو التغير الأي أخذه هيكل عن هرقليطس، وهو يعني أن كل شيء في تغير ولا

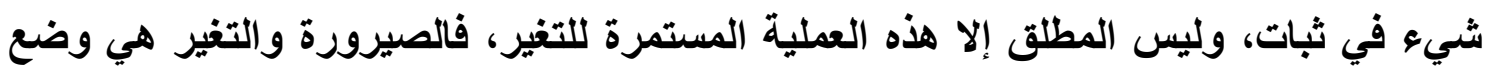
الوجود الحق، والتغير هو حال الوجود على وجه الصواب(ه؛). وهكذا تناظر فلسفة هيكل أفكار

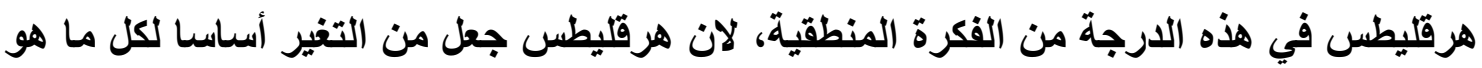
موجود، وهذا هو حال تطور الفكر القلسفي وانتقاله من جيل إلى جيل.

يقول هيكل في هذا الصدد أن الماهية المشتركة، أي القانون العلوي الظاهر تتوفر لها

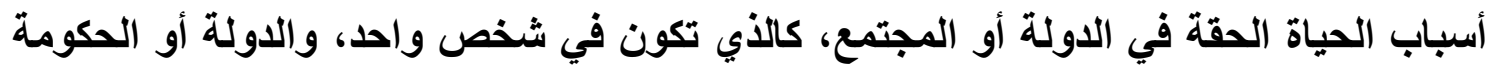
أنما هي الروح الحق المتفكرة في ذاتها، وهذه الروح تسمح للماهية أن تهب كل جزء(فرد)، قيمته وكونه (كيانه الخاص). وعلى الرغم من أن الأسرة هي عنصر الواقع في المجتمع لكن

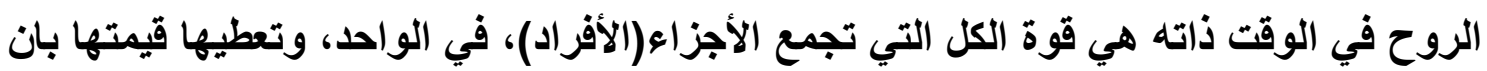
لا حياة لها ألا في الكل (الروح المطلق)، وبوسع الماهية أن تنتظم في انساق للاستقلال الفردي أو الملكية للأفراد والأشياء(بَ؛).

الخملاصةة:

يكاد يجمع معظم الباحثين والمفكرين في حقل الفلسفة أن للفكر اليوناني القديم، اثر واضح في الفكر القلسفي الحديث والمعاصر لا يمكن تجاهله، فبعد أفول نجم القلسفة اليونانية في بلاد اليونان خاصة في أثينا، انتشرت في البلدان المجاورة، وامتزجت بالفكر الثرقي القديم(الديني بشكل خاص)، مما ساعد في مساهمة الثرقيين بالفكر القلسفي، وازدهار مدن الشرق بالقلسفة، وقيام المدارس القلسفية فيها، كالإسكندرية، ورودس، وميغارا، وقورينا، وسعى الكثير من الفلاسفة إلى تجديد المذاهب القلسفية القديمة، مع عناية خاصة بالأخلاق، فسعت الابيقورية إلى تجديد مذهب ديمقريطس في الأرات، وتبنت الرواقية فكرة اللوغوس عند هرقليطس، وطور الثكاك القاعدة السفسطائية التي تعد الإنسان مقياس الأثياء جميعا، ثماني حاولت الأفلاطونية الجديدة، وضع فلسفة دينية جديدة هي مزيج من الاين القلسفة، قامت على الفي أصول فلسفة أفلاطون وعناصر من الايانات الثرقية، حاولت الاحتفاظ بالروح اليونانية المتمثلة بالعقلية العلمية في تفسير الأثياء. ثم شرح مجموعة من الفلاسفة الفكر الأرسطي،

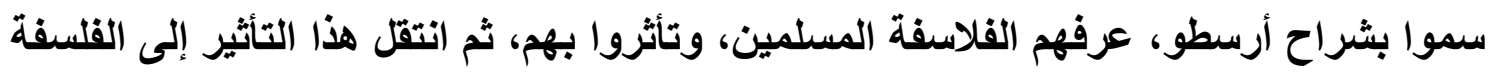
الغربية بعد أن ترجمت كتب الفلاسفة المسلمين إلى اللغات الأوربية. وفي العصر الوسيط (الفكر المسيحي والإسلامي)، بدأت القلسفة اليونانية تتبعث من جديد، فقد تبنى الفلاسفة في هذا العصر شرح الفلسفة اليونانية برؤية جديدة اقرب إلى الدين 


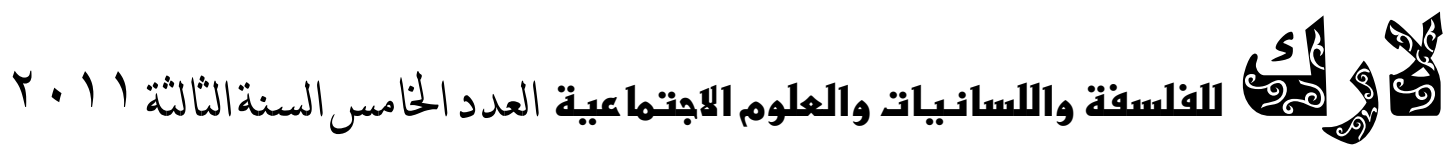

منها إلى القلسفة، ووظقوها لخدمة الاين، وسعوا إلى استنطاقها بأحكام دينية في مشكلات

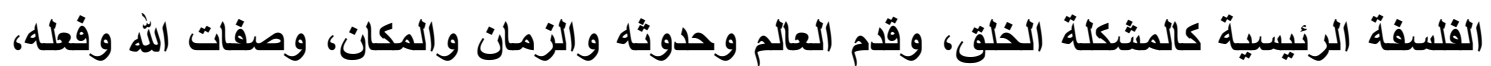
وتتاهي جرم العالم، ومشكلات الميتافيزيقا بشكل عام.

وفي العصر الحديث حاول معظم الفلاسفة أحياء الفكر اليوناني، وعده الكثير من المفكرين المنطلق الأول للفعل الإنساني في كثف حقائق الوجود العلمية، وبناء المذاهب القلسفية، واخذ

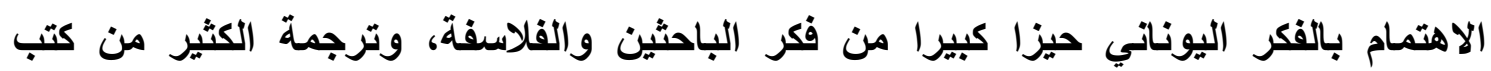

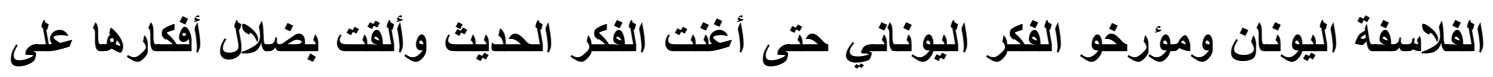
تصورات فلاسفته وهيمنت على عقولهم.

لقد أثبتت الدراسات الحديثة أن التاريخ يتطور عبر مراحل وحلقات يرتبط بعضها ببعض، وهذا القول ينطبق أيضا على تاريخ العلم والقلسفة، بحيث لا نجد فكرة فلسفية حديثة إلا ولها

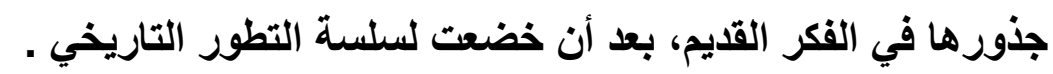
أن نظرة فاحصة لمسار الفكر الفلسفي الحديث والمعاصر، يمكن الاستنتاج منها، أن معظم الأفكار القلسفية التي ظهرث في هاتين العصرين لا تخلو من اثر من الفكر اليوناني القديم، وان

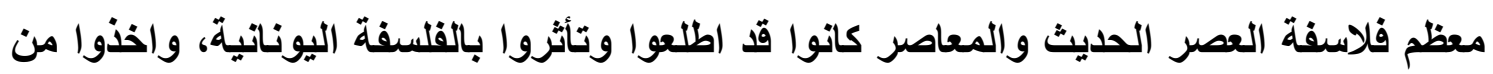
أفكار ها في بناء مذاهبهم في القلسفة، لقد قامت فلسفة هيكل، موضوع بحثنا على فكرة الصراع

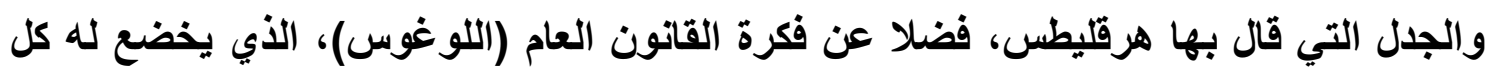
صراع في الوجود، فهو ثابت، لا يخضع للتغير الأي يحصل على بقية الأشياء في الوجود، وهو ما يقابل مفهوم العدالة الكونية عند هيكل الأي تثمثل بالروح الكلية أو العقل المطلق الذي لأي يخضع له كل شيء، ويتحكم في كل تغير في الوجود.

يرى فردريك نيتشه، أن علينا التميز بين البداية والأصل، لأنه ليس ممكن الحديث عن الأصل، لان كل أصل عبارة تأويل لنموذج سابق عليه، وهكذا كاتت معظم فلسفة هيكل تأويل لنموذج سابق عليها، وهي أراء هرقليطس في الفلسفة.

الهوامش

ا. 1 ـ هـ. ارمسترونغ، مدخل إلى القلسفة القديمة، ترجمة سعيد الغانمي، المركز الثقافي

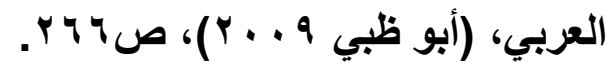




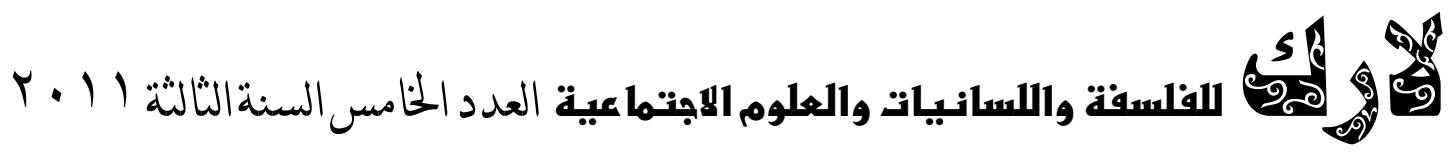

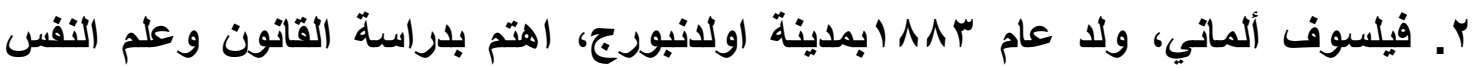
وأبدع في الفلسفة وكان أكثر الفلاسفة الألمان المعاصرين أنتاجا، انظر: زكريا إبراهيم، دراسات

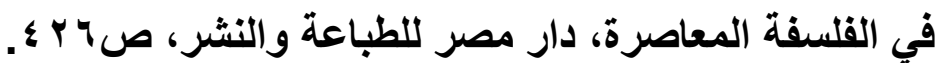
r. فيلسوف فرنسي يعد من أعلام القلسفة الوجودية الفرنسية المسيحية، ولا في باريس عام

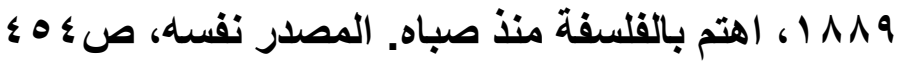
ع. يوسف كرم، تاريخ القلسفة الحديثة، مكتبة الدراسات القلسفية، دار المعارف، القاهرة . هـ الموسوعة القلسفية العربية، معهد الإنماء القومي، المجلد الثاني، القسم الثاني، تحريز معن

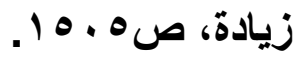

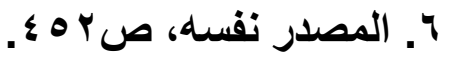

$$
\begin{aligned}
& \text { V. المصدر نفسه، صوه هـ ع. }
\end{aligned}
$$

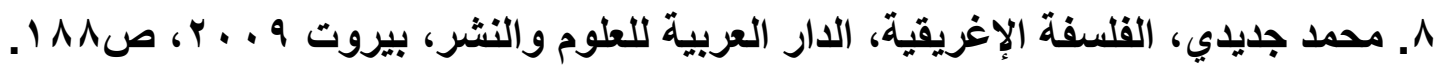

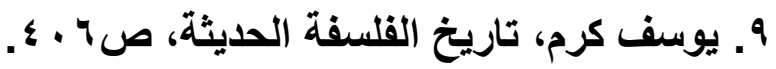

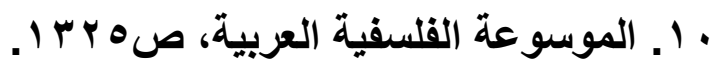

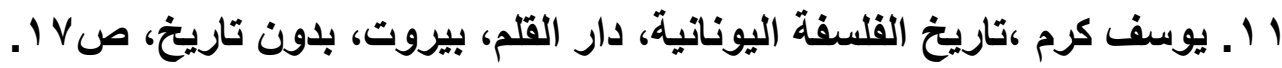

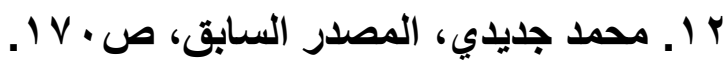
با ـ المصدر نفسه، ص. V. . . وقارن: جورج طرابيشي، معجم الفلاسفة، دار الطليعة للطباعة

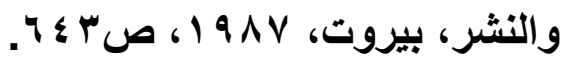
ع ا. فردريك نيتشه، القلسفة في العصر المأساوي الإغريقي، تعريب سهيل القش، الطبعة

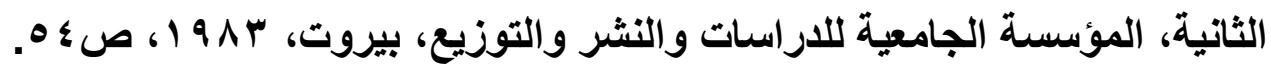

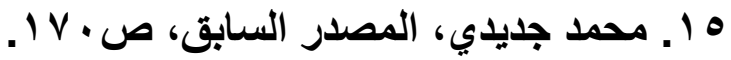

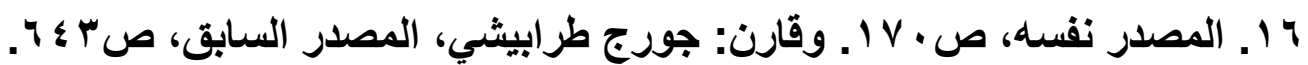
V V الموسوعة القلسفية المختصرة، ترجمة، فؤاد كامل وآخرون، مكتبة النهضة، بغدادة، .01 r ص (919r

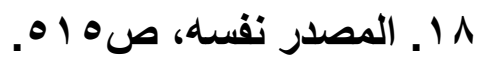

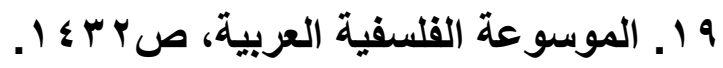

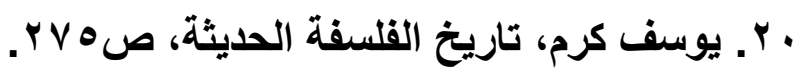

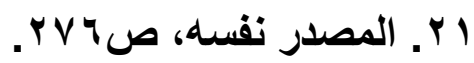

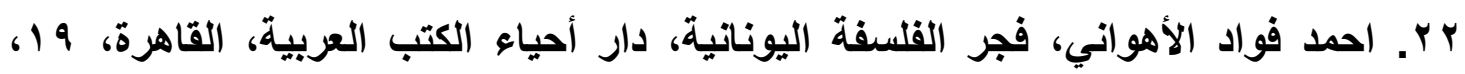

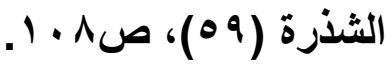




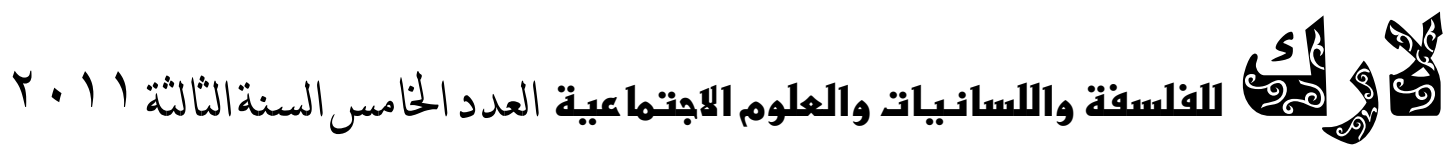

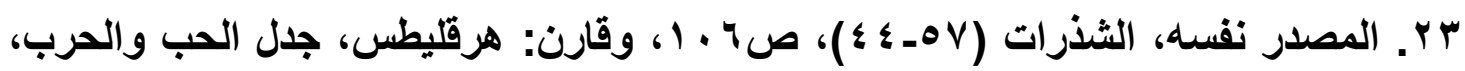
ترجمة وتقديم وتعليق: مجاهد عبد المنعم مجاهد، دار الثقافة للطباعة والنشر، القاهرة،

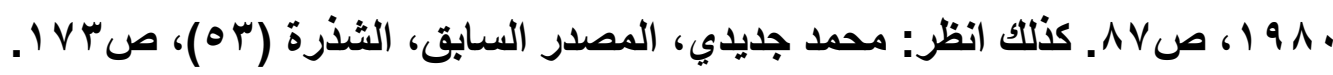

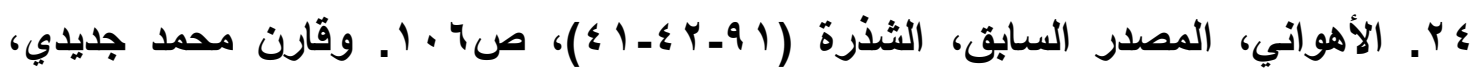

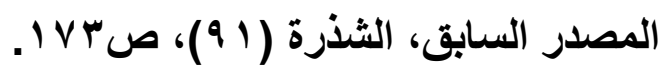
ه ب. وولتز ستيس، تاريخ القلسفة اليونانية، ترجمة مجاهد عبد المنعم مجاهد، دار الثقافة

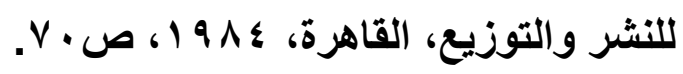

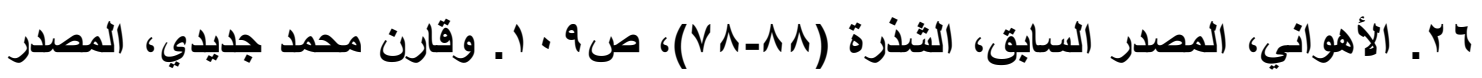

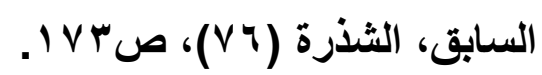

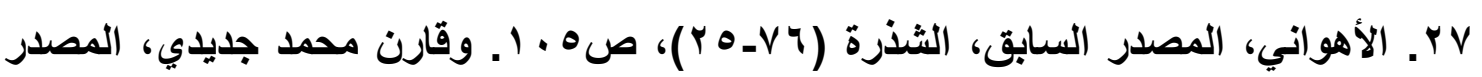

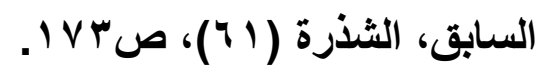

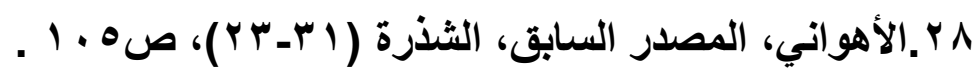

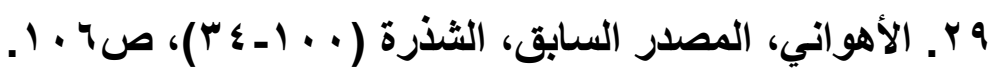

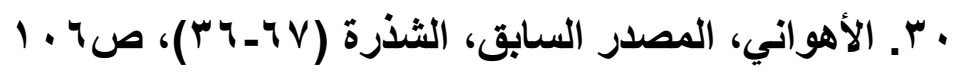

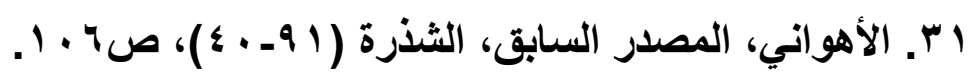

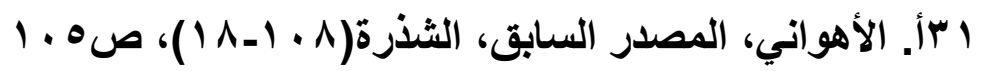
ץ ب. إمام عبد الفتاح إمام، دراسات في القلسفة السياسية عند هيكل، دار الثقافة للنشر

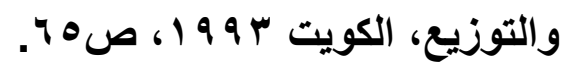

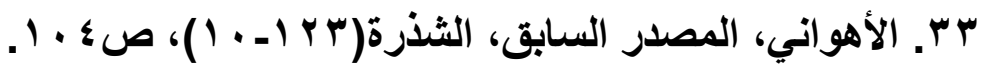

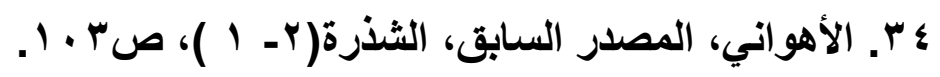

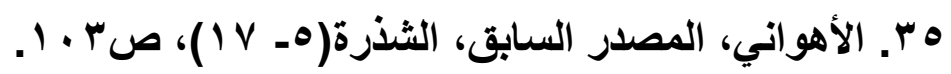

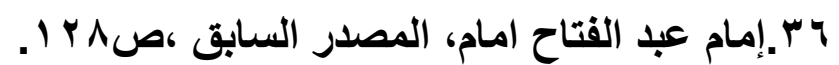

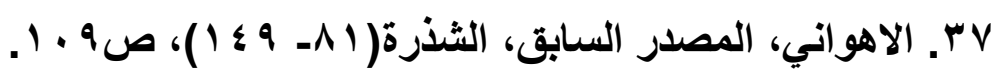

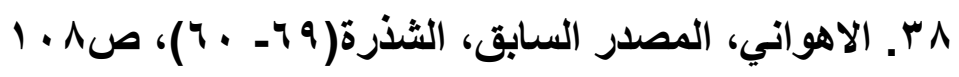

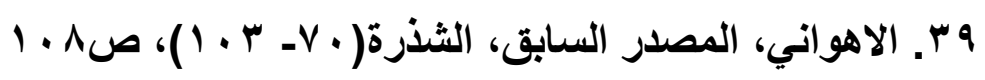

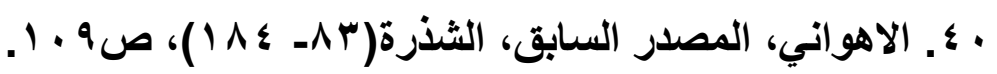
اء ـ ولتر ستيس، هيكل(المنطق وفلسفة الطبيعة)، المكتبة الهيكلية، ثرجمة امام عبد القتاح

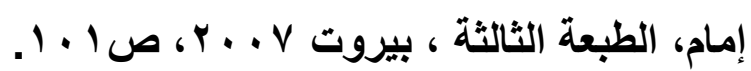

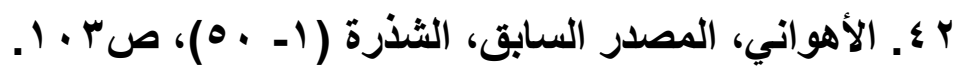

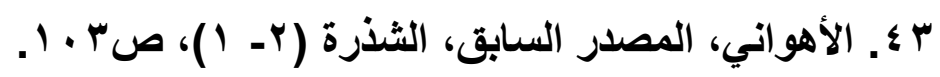




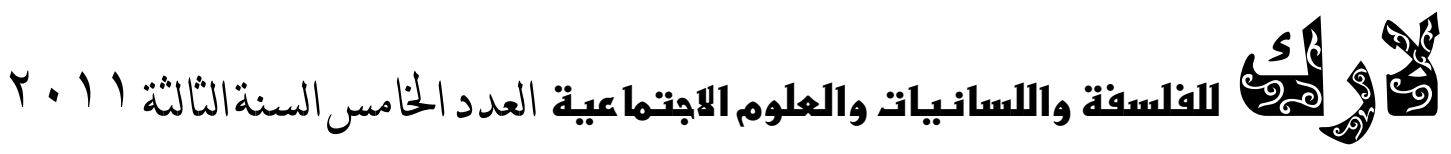

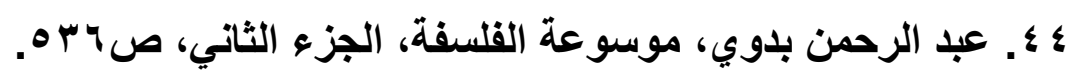

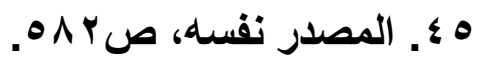

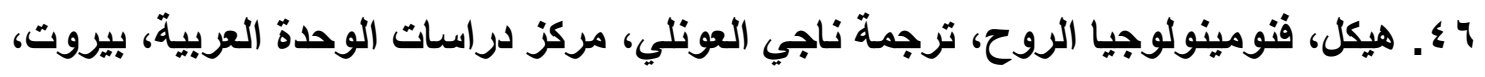

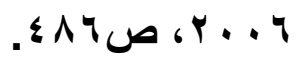

